\title{
The Elasticity of the Epidemic Growth Rate to Observed Weather Patterns with an Application to Yellow Rust
}

\author{
F. van den Berg and F. van den Bosch
}

Department of Biomathematics and Bioinformatics, Rothamsted Research, Harpenden, Hertfordshire AL5 2JQ, UK. Accepted for publication 19 July 2007.

\begin{abstract}
Van den Berg, F., and van den Bosch, F. 2007. The elasticity of the epidemic growth rate to observed weather patterns with an application to yellow rust. Phytopathology 97:1512-1518.

We extend a previously developed method that quantifies the sensitivity of the exponential epidemic growth rate, $r$, to weather changes, through a pathogen's life cycle components (basic reproduction number, latent period, and mean and standard deviation of the spore production curve). Here a method is developed to study the elasticities of the system and subsequently the model is linked to observed weather patterns. This enables a direct comparison between the effects of different weather variables (temperature, surface wetness duration, and light quantity) under realistic weather scenarios. The three sites studied represent areas

by Puccinia striiformis, on winter wheat is studied as a key application. Our results show that temperature and more importantly changes in temperature through their effect on pathogen reproduction have the largest effect on $r$. The long latent period at low winter temperatures is not a key component in the epidemic development, which is contrary to general beliefs. The results combined with long term average yellow rust severity patterns show that it is winter survival and not summer survival that controls the eventual disease severity. The results also show that within the current United Kingdom spraying regime on wheat crops against yellow rust, the first spray should mainly affect the basic reproduction number, i.e., should be a protectant spray, whereas the second spray should also affect the latent period, i.e., should also have curative action.
\end{abstract} within the United Kingdom with contrasting climates. Yellow rust, caused
Weather is an important factor influencing the development of most plant pathogens $(3,5,11,12,18)$. Several models of plant pathogen epidemiology, incorporating weather variables, have been published $(13,16,18,25)$, but each of these models has its own structure which makes it difficult to compare the outputs of these models. Moreover, most of these models only show how changes in weather variables affect the growth rate of the pathogen population without distinguishing between the effects of the various life cycle components. In other words, these models do not identify the life cycle components of the pathogen through which the change in the weather variable has the largest effect on the growth rate of the pathogen population.

The method recently developed by Papastamati and van den Bosch (16), based on the work by Segarra et al. (20), defines the sensitivity of the growth rate of the pathogen population to changes in weather variables through the individual life cycle components. Moreover, this model is generic, based around the Euler equation, and can be applied to a wide range of plant pathogens as long as the functions for the weather dependent life cycle components can be defined and parameterized. This allows the comparison of pathogens by one standardized method.

Papastamati and van den Bosch (16) use sensitivity, defined as the change in the rate of epidemic increase, $r$, resulting from one unit increase in the weather variable, $X$, and denoted by $\partial r / \partial X$. However, because the weather variables are measured at different and thus incomparable scales, this analysis cannot be used to compare the effects of different weather variables. They also do not consider the effect of changing multiple weather variables simultaneously, nor do they link their model to observed weather

Corresponding author: F. van den Berg

E-mail address: femke.vandenberg@bbsrc.ac.uk

doi:10.1094/PHYTO-97-11-1512

(C) 2007 The American Phytopathological Society patterns. Park (17), however, has shown that this approach can lead to incorrect conclusions. Firstly, the ranges of weather variables tested in experiments and models might not reflect the ranges experienced by the pathogen under field conditions. Secondly, weather variables are not independent but rather occur as weather patterns specific to place and time. Since it is the combination of weather variables that determines the epidemic growth rate, studying single variables in isolation will not give a correct overview of the effects of weather changes on the pathogen population development.

To solve these problems we will firstly introduce an elasticity analysis, based on the methods previously described by Caswell (1), to determine which weather variables and which life cycle components have the strongest effect on the rate of increase of the pathogen population. Elasticity is defined as the proportional sensitivity, i.e., the proportional response of the rate of epidemic increase, $r$, to a proportional perturbation in a weather variable, $X$, denoted by

$$
\frac{\partial r}{\partial X} \frac{X}{r}
$$

In contrast to a sensitivity analysis, an elasticity analysis does allow for the direct comparison of the effects of different weather variables.

Secondly, this method will be linked to observed weather patterns which will enable the comparison of different sites/climates by varying multiple weather variables simultaneously within relevant ranges for these sites/climates. We thus gain insight about which time of the year the pathogen population growth rate is most affected by changes in weather variables and through which life cycle component this effect is constituted.

Short time scale weather patterns, including surface wetness duration data, are now available from an increasing number of weather stations. We study yellow rust, caused by Puccinia striiformis, on winter wheat as a key application and will compare our results with the available literature on this pathosystem. The de- 
pendencies of the life cycle components of yellow rust on favorable weather conditions, especially temperature, surface wetness duration and light quantity, have been described in detail $(4,6$, $15,19,23)$. However, there is no clear overview on how the different weather variables interact and thus how this interaction enhances or reduces the overall effect on the pathogen population growth rate.

In this paper we thus extend the method described by Papastamati and van den Bosch (16) and use weather patterns from the Environmental Change Network (ECN) for three United Kingdom sites to analyze the elasticity to different weather variables through different life cycle components of yellow rust growth across the year. Surface wetness duration is a difficult variable to measure, especially in the field (10), and therefore its measurement and inclusion in the ECN database provides us a unique set of weather patterns for our analysis.

\section{THEORY AND APPROACHES}

As discussed by Segarra et al. (20) and Papastamati and van den Bosch (16), the Euler equation provides a generic method to calculate the exponential population growth rate, $r$, of a pathogen from the pathogen's life cycle components and its interactions with the host. The Euler equation is given by

$$
1=R_{0} \int_{0}^{\infty} i(a) e^{-r a} d a
$$

where $R_{0}$ is the basic reproduction number and $i(a)$ is the normalized sporulation curve (20). Once the basic reproduction number and the normalized sporulation curve are defined as a function of the pathogen's life cycle components, the model can be parameterized to describe a specific pathogen.

Using data published by McGregor and Manners (15) Papastamati and van den Bosch (16) showed that for yellow rust, the spore production curve is well described by a delayed gamma distribution function

$$
i(a)=\frac{\lambda[\lambda(a-p)]^{n-1} e^{(-\lambda(a-p))}}{\Gamma(n)}
$$

whereby $p$ is the latent period, $\Gamma(n)$ is the gamma function and the mean, $\mu$, and the standard deviation, $\sigma$, of the gamma distribution are functions of the gamma distribution parameters $n$ and $\lambda$ such that $\mu=n / \lambda$ and $\sigma^{2}=n / \lambda$. The latent period, $p$, mean, $\mu$, and standard deviation, $\sigma$, of the spore production curve solely depend on temperature, $T$. The basic reproduction number, $R_{0}$, of yellow rust is given by the fraction of spores deposited on a leaf, times the infection efficiency, times the spore production per lesion whereby the spore production depends on temperature, $T$, and the infection efficiency depends on temperature, $T$, surface wetness, $W$, and light quantity, $L(5)$. The exponential population growth rate, $r$, of yellow rust is thus a function of the life cycle components, $R_{0}, p, \mu$, and $\sigma$, which are themselves functions of the weather variables. In equation form:

$$
r=f\left(R_{0}(T, W, L), p(T), \mu(T), \sigma(T)\right)
$$

Combining all this information, the Euler equation for yellow rust becomes

$$
\left.R_{0}(T, W, L) e^{-r(T, W, L) p(T)}\left[\frac{1}{\left(r(T, W, L) \sigma^{2}(T) / \mu(T)\right.}+1\right)\right]=1
$$

See Papastamati and van den Bosch (16) for a derivation of equation 4. Table 1 gives an overview of all parameters and functions in equation 4 , as derived for yellow rust $(5,15,16)$.

Papastamati and van den Bosch (16) show that the sensitivity of the exponential population growth rate, $r$, to a weather variable, $X$, is calculated from

$$
\frac{\partial r}{\partial X}=-\left[\left(\frac{\partial r}{\partial R_{0}} \frac{\partial R_{0}}{\partial X}\right)+\left(\frac{\partial r}{\partial p} \frac{\partial p}{\partial X}\right)+\left(\frac{\partial r}{\partial \mu} \frac{\partial \mu}{\partial X}\right)+\left(\frac{\partial r}{\partial \sigma} \frac{\partial \sigma}{\partial X}\right)\right]
$$

where $X \in\{T, W, L\}$. This equation can be interpreted as follows: the first product on the right side of equation 5 denotes the sensitivity of $r$ to a change in $X$ through the effect that the change in $X$ first had on $R_{0}$ and the remaining terms describe its sensitivity through $p, \mu$, and $\sigma$. The sensitivity of $r$ to a change in a weather variable is, therefore, the sum of the effects of a change in this weather variable through its effect on each individual life cycle component, $R_{0}, p, \mu$, and $\sigma$.

As explained in the introduction, we are interested in the elasticity (not the sensitivity) of $r$ to the weather variables through

TABLE 1. Variable and function definitions; the functions were fitted to data as previously described by Papastamati et al. (16)

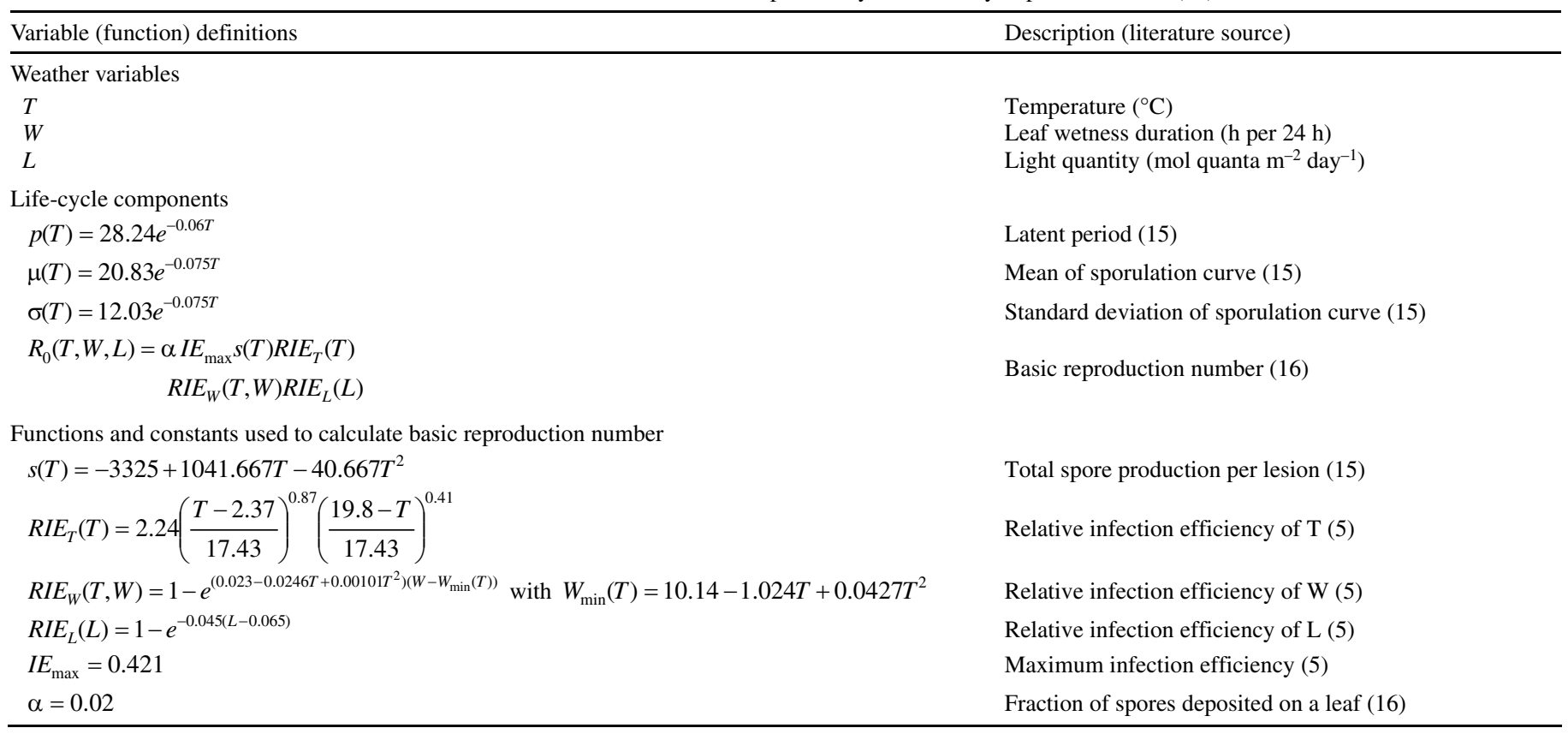


the individual life cycle components, as elasticities are scaled independently and thus allow for comparison between the effects of the different weather variables. Two types of elasticity will be studied in this paper. Firstly, the elasticity of $r$ to a weather variable relative to the elasticity of $r$ to all weather variables, $e_{X}$, with $X \in\{T, W, L\}$. For example, the relative elasticity of $r$ to temperature is

$$
e_{T}=\frac{\left|\frac{\partial r}{\partial T} \frac{T}{r}\right|}{\left|\frac{\partial r}{\partial T} \frac{T}{r}\right|+\left|\frac{\partial r}{\partial L} \frac{L}{r}\right|+\left|\frac{\partial r}{\partial W} \frac{W}{r}\right|}=\frac{\left|\frac{\partial r}{\partial T} T\right|}{\left|\frac{\partial r}{\partial T} T\right|+\left|\frac{\partial r}{\partial L} L\right|+\left|\frac{\partial r}{\partial W} W\right|}
$$

Secondly, the elasticity of $r$ to a weather variable through one life history component relative to the elasticity of $r$ to all weather variables through all life history component, $e_{X(H)}$, with $X \in$ $\{T, W, L\}$ and $H \in\left\{R_{0}, p, \mu, \sigma\right\}$. For example, the relative elasticity of $r$ to temperature through its effect on the latent period, $p$, is

$$
\begin{aligned}
e_{T(p)}= & \frac{|T \partial r / \partial p \partial p / \partial T|}{M} \\
M= & |T \partial r / \partial p \partial / \partial T|+|T \partial r / \partial \mu \partial \mu / \partial T|+|T \partial r / \partial \sigma \partial \sigma / \partial T|+\left|T \partial r / \partial R_{0} \partial R_{0} / \partial T\right|+ \\
& \left|W \partial r / \partial R_{0} \partial R_{0} / \partial W\right|+\left|L \partial r / \partial R_{0} \partial R_{0} / \partial L\right|
\end{aligned}
$$

Weather data. Weather data were collected from the ECN automatic weather stations in the United Kingdom (information available online by the ECN). The sites studied are (i) North Wyke in Devon, South West England, (ii) Rothamsted in Hertfordshire, South East England, and (iii) Glensaugh in Aberdeenshire, Scotland. Wheat is cultivated at all three locations and the three sites represent contrasting weather environments in the United Kingdom. Weather data were available for the years 1996 to 2003, 1995 to 2004, and 1996 to 2005 for North Wyke, Rothamsted, and Glensaugh, respectively. Table 2 provides a detailed description of the weather variables and the unit conversion applied.

\section{RESULTS}

Weather patterns and wheat growth. The weather patterns are qualitatively the same for all sites (Fig. 1). Of the three sites analyzed, Rothamsted is on average the warmest and driest site that also, on average, receives the highest amount of light; followed by North Wyke and then Glensaugh. The standard errors of the average variable values are relatively small. Wetness does however show larger standard errors, especially for the wettest site (Fig. 1B, E, and $\mathrm{H}$ ).

To put the results of the elasticity analysis into perspective we describe wheat growth in Figure 1J. Above-ground wheat biomass is only present for a third of the year. Spraying normally takes place just after the appearance of the fist node (spray 1; protective control) and when the flag leaf has appeared (spray 2; eradicating

TABLE 2. Weather variable description and unit definition ${ }^{\mathrm{a}}$

\begin{tabular}{lccl}
\hline Weather variable & Symbol & Units (ECN data) & Units (this paper) \\
\hline Temperature & $T$ & ${ }^{\circ} \mathrm{C}^{\mathrm{b}}$ & ${ }^{\circ} \mathrm{C}^{\mathrm{b}}$ \\
Surface wetness & $W$ & $\mathrm{~min} \mathrm{~h}^{-1}$ & $\mathrm{~h} \mathrm{day}^{-1}$ \\
Light quantity & $L$ & $\mathrm{~W} \mathrm{~m}^{-2}$ & mol(quanta) $\mathrm{m}^{-2}$ day $^{-1 \mathrm{c}}$ \\
\hline
\end{tabular}

${ }^{a}$ All Environmental Change Network (ECN)-weather station data were measured hourly and have been converted into daily averages for the elasticity calculations.

${ }^{\mathrm{b}}$ Dry bulb temperature.

${ }^{c}$ One unit of solar radiation $\left(\mathrm{W} \mathrm{m}^{-2}\right)$ is roughly equal to $0.5 \pm 0.02 \mathrm{~W} \mathrm{~m}^{-2}$ photosynthetically active radiation (PAR) $(7,22)$ and one unit of PAR is roughly equal to $4.6 \times 10^{-3} \mathrm{~mol}$ (quanta) $\mathrm{m}^{-2}$ (14). control), i.e., in the first one and a half month of the growing season.

Effects of weather variables on elasticity of exponential growth rate, $\boldsymbol{r}$. Overall effects of weather variables. The exponential growth rate of the pathogen is most affected by changes in temperature, followed by changes in the surface wetness duration (Fig. 2A, D, and G). At the warmest site, i.e., Rothamsted, changes in temperature and surface wetness duration have equally large effects on the pathogen population growth rate in early and late summer (Fig. 2A), whereas at North Wyke they are equal during mid-summer (Fig. 2D). At the coolest site, i.e., Glensaugh, temperature has a larger effect on the pathogen population growth rate than surface wetness duration throughout the year (Fig. 2G). Changes in light quantity have the least impact on the pathogen population growth rate throughout the year. At the Rothamsted site, the elasticity of the pathogen population growth rate, $r$, to temperature becomes decreasingly important from winter to early summer, peaks over the summer months, dips at the end of summer to slowly increase again over the autumn months (Fig. $2 \mathrm{~A})$. The peak in the elasticity of $r$ to temperature over the summer at Rothamsted is found at neither North Wyke nor Glensaugh (Fig. 2D and G). The patterns of the elasticity of $r$ to surface wetness duration across the year are opposite to those found for temperature. Note that at the coldest and wettest site (i.e., Glensaugh) the difference between the effect of temperature and surface wetness has increased rather than decreased (compare Fig. $2 \mathrm{D}$ and G). The impact of changes in light quantity on the pathogen population growth rate is largest over the winter months.

Effects of weather variables through the life cycle components. Overall the elasticity of $r$ to temperature through the basic reproduction number, $R_{0}$, is by far the largest, followed by the elasticity of $r$ to the surface wetness duration through the basic reproduction number (Fig. 2B, E, and H). In general, but with some exceptions for Glensaugh, the pathogen population growth rate is most affected by changes in temperature through the basic reproduction number between November and April, and between July and August. In May, June, September, and October, the elasticity of $r$ to temperature through the basic reproduction number and the elasticity of $r$ to surface wetness duration through the basic reproduction number are roughly equal. With decreasing average site temperature and increasing average site wetness, i.e., from Rothamsted to Glensaugh, the differences between the elasticities of the individual life cycle components become smaller over summer.

As mentioned earlier, some exceptions to these general patterns are found at Glensaugh. For this site, the three factors most strongly affecting the pathogen population growth rate due to changes in the weather variables during the summer (i.e., the elasticity to temperature through the basic reproduction number and the latent period, and the elasticity to wetness duration through the basic reproduction number) have roughly the same elasticities (Fig. 2H). Furthermore, at Glensaugh the elasticities of $r$ to temperature and the surface wetness duration through the basic reproduction number are roughly equal between June and September compared with May, June, September, and October for the other two sites.

\section{DISCUSSION}

Extending the model, as defined by Segarra et al. (20) and Papastamati and van den Bosch (16), by linking it to observed weather patterns and subsequently performing an elasticity analysis enabled us to directly compare the effect of changes in weather variables (through the individual life cycle components) on the pathogen population growth rate. Here we will show that this makes it possible to dispel some misconceptions and/or give more insight in previous findings about the effect of weather variables on the growth rate of yellow rust epidemics. The Euler 
equation is a very generic method to calculate the pathogen population growth rate, $r$. The definition of the normalized spore production curve and the weather dependent life history components are pathogen species specific. For example, for certain species it might be necessary to include other weather variables like rain and wind speed (for Septoria tritici and powdery mildew, respectively [23]), which might lead to the latent period and the infectious period no longer depending on temperature only. Also, the normalized spore production of some species might be better described by a more simplified model, e.g., the Vanderplank model (20), which assumes a constant spore production rate throughout the infectious period. Since data on weather dependent spore production is often limited, the Vanderplank model is often easier to parameterize. Although these species dependent functions change equation 4 and the derivatives as described in equation 5 will have to be recalculated, the methods developed throughout this paper do not change. The model can thus easily be adapted to compare different pathogen systems. We are aware that the weather dependent life history components might be site specific, but a lack of site specific data has not allowed us to take this into account.

Changes in temperature have largest effect on development of yellow rust epidemic. The epidemic growth rate of yellow rust is most sensitive to temperature and this pattern is observed across all sites and across the whole year (Fig. 2A, D, and G). Many others have come to the same conclusion $(2,23)$.

In winter, the elasticity to temperature through the basic reproduction number, $R_{0}$, is large. At the warmer sites the elasticity to temperature through the basic reproduction number peaks in summer because temperature becomes too high for successful spore production. This effect is so strong that it overshadows all other effects. Effects of high temperatures over summer have been identified before, even under field conditions $(2,8,26)$, but so far it has not been clear which life cycle component contributed the most. Note that at these warm sites, an increase in temperature has a negative effect on the reproduction number and thus the
ROTHAMSTED
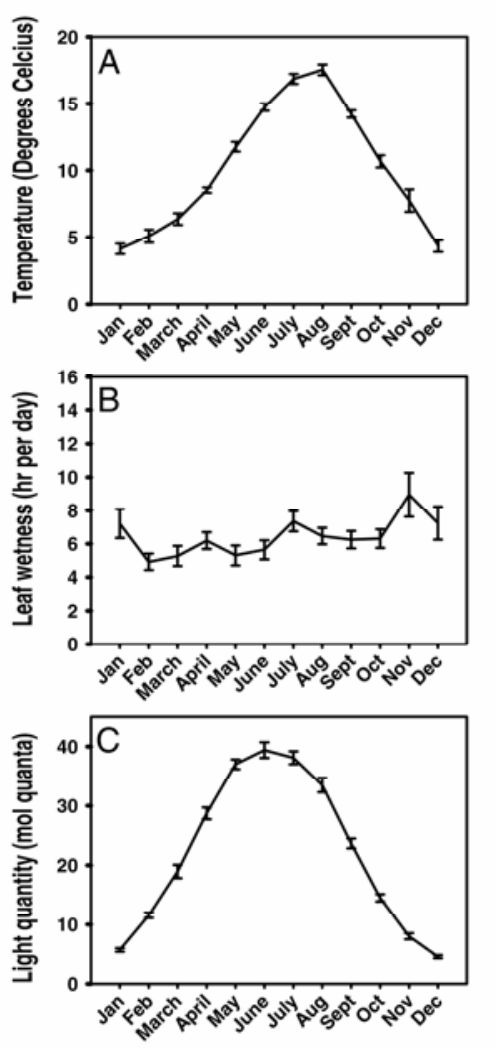

NORTH WYKE
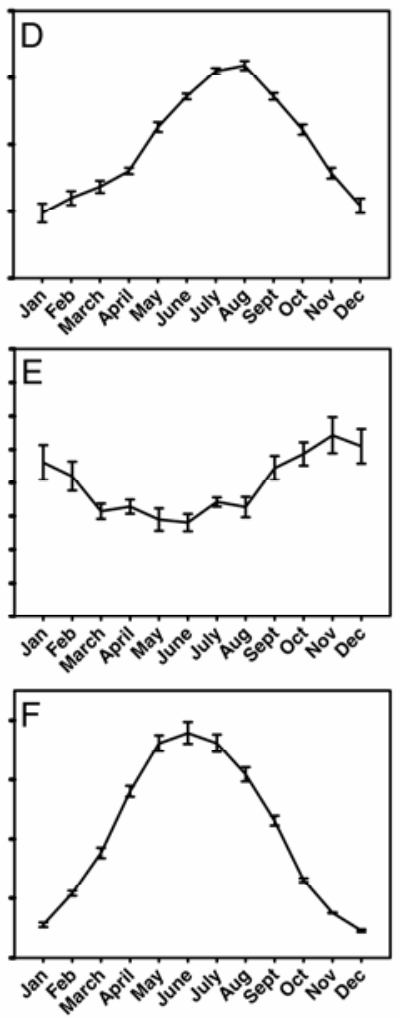

GLENSAUGH
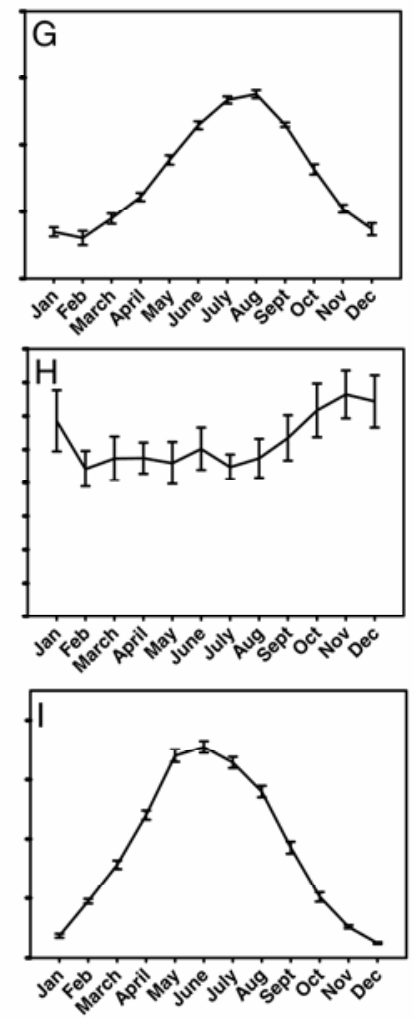

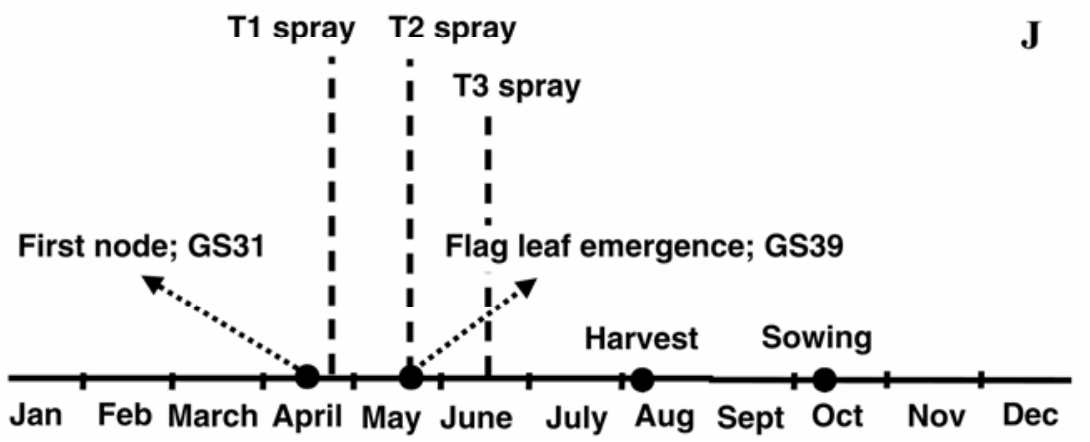

Fig. 1. Monthly averages of the weather data for the three United Kingdom sites: A to C, Rothamsted, D to F, North Wyke, and G to I, Glensaugh. A, D, and G show temperature $(T)$ in degrees Celcius, B, E, and $\mathbf{H}$ show leaf wetness duration $(W)$ in hours per day, and $\mathbf{C}$, $\mathbf{F}$, and $\mathbf{I}$ show light quantity $(L)$ in mol quanta per $\mathrm{m}^{2}$ per day. Error bars give one standard error of the mean of all available data years. J, Schematic overview of some marked crop growth stages (GS), average dates for harvesting, sowing dates, and the three commonly adopted sprays (T1-T3) for yellow rust on wheat. 
pathogen population growth rate during summer, whereas it has a positive effect during the rest of the year. At the coolest site, an increased temperature has a positive effect throughout the year.

At the coolest site, these effects of high temperature on spore production over the summer are not observed. At the coolest site, the population growth rate of yellow rust is still most affected by temperature changes (Fig. 2G) as temperature is the only weather variable affecting multiple life cycle components and because, despite the decrease in the elasticity to temperature through the basic reproduction number over summer, the elasticities to all other life cycle components affected by temperature are increasing considerably over this period (Fig. $2 \mathrm{H}$ and I). Note that at the coolest site, the surface wetness duration has also increased (Fig. $1 \mathrm{~B}$ and $\mathrm{E}$ versus $\mathrm{H}$ ). If this would not have been the case, surface wetness duration would likely have become limiting over summer and thus have resulted in the surface wetness duration through the basic reproduction number having the largest elasticity, which was already indirectly suggested by Zadoks' (26) findings.

Gareth-Jones and Clifford (8) described the yellow rust epidemic by a rapid increase in the pathogen population development in early spring with severe disease levels evident in May. Over summer, further infection cycles were often observed, but these were limited by the hot and dry summer weather. Our results seem to underpin this statement well, except for the fact that at the warmer sites and in warmer years, it is the effect of temperature changes alone that curtails the pathogen population growth rate.

Validity of the use of averages. Our results are based on average temperatures, which could be misleading as identical mean values might be the result of completely different tempera- tures $(2,11)$. For example, when analyzing yellow rust epidemics, two medium hot days both suitable for infection are much worse than one very hot day, limiting spore production, and one much cooler day enabling infection, despite resulting in the same mean temperature. As Kranz and Rotem (11) mentioned daily mean temperatures are, however, still suited as a starting point for the disease weather interactions over a relatively large time scale, e.g., a year. The fact that our weather data span over multiple years also strengthens our results.

Similarly, one could speculate whether the use of average elasticities is correct, as one extreme elasticity could overshadow the effect of all others by taking averages. There are several reasons to assume that these extreme elasticities do not occur or significantly change the model findings. Firstly, the weather variability within each month and across years was relatively low and averaging over multiple years did not significantly change the yearly trends (results not shown). This suggests that there are no sudden extreme changes in the weather that could lead to extreme elasticities. Secondly, for several site-years a count was made of the number of times a month that one specific weather variable and life history trait combination had the largest elasticity. The trends found by this method were very similar (results not shown).

The long latent period at low temperatures is not relevant to the epidemic development over winter. It is well known that the latent period of yellow rust increases drastically when temperatures are low $(15,19,26)$ and this can clearly be seen in the winter months of all three sites studied (data not shown). Unlike the latent period, the basic reproduction number is difficult to measure, especially at low temperatures, in both field and
ROTHAMSTED
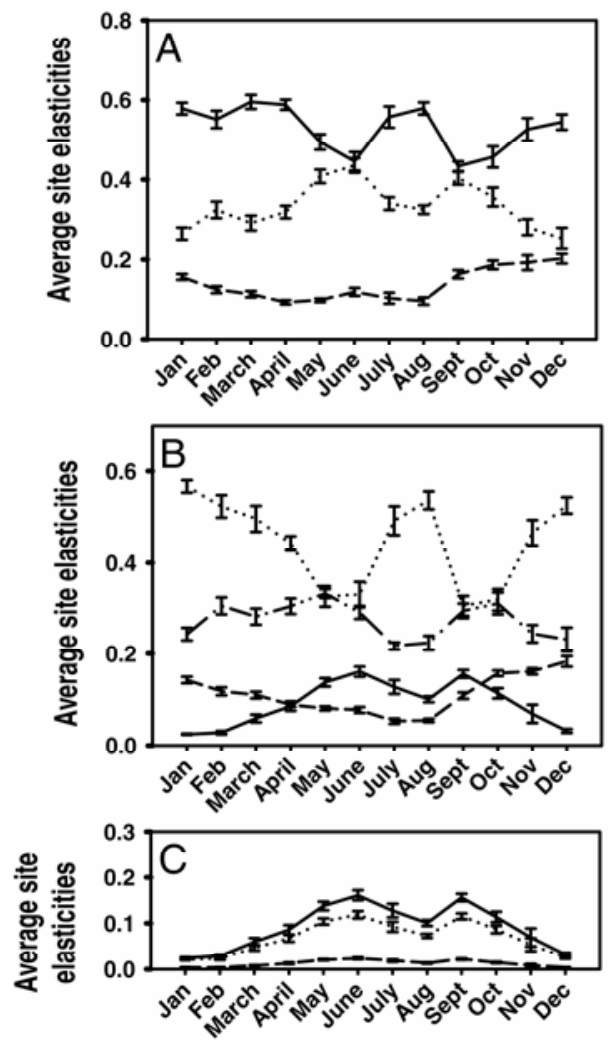

NORTH WYKE
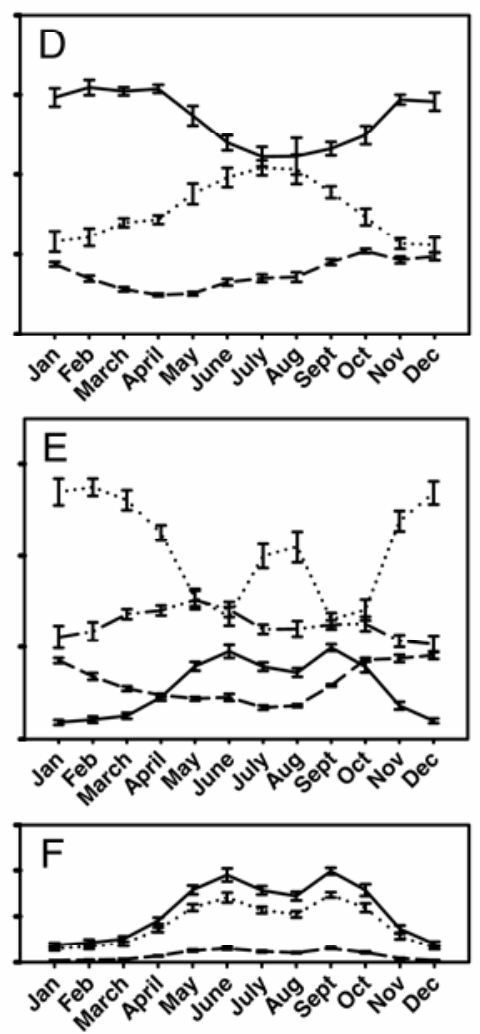

\section{GLENSAUGH}

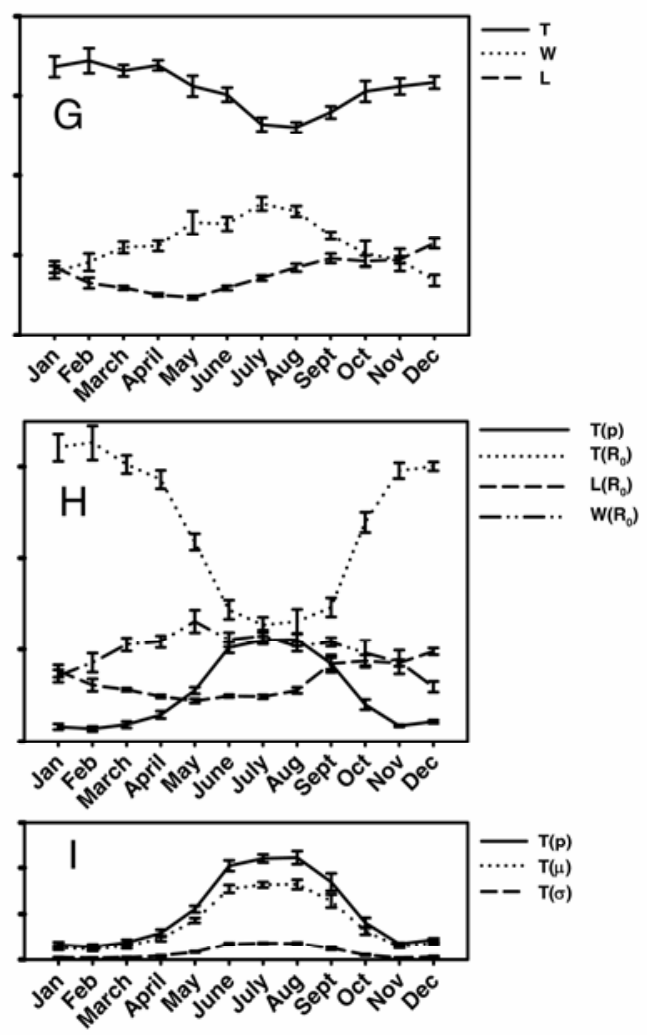

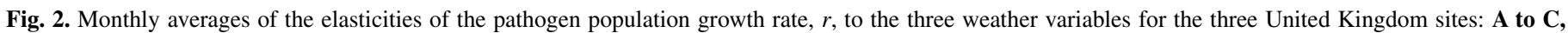

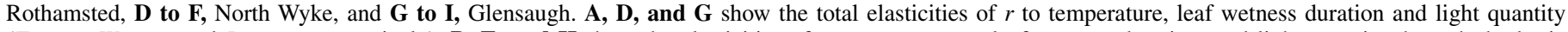

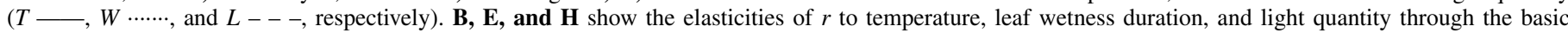

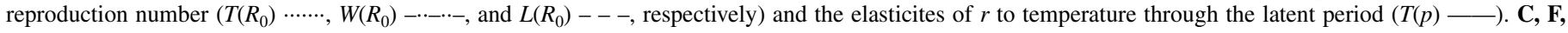

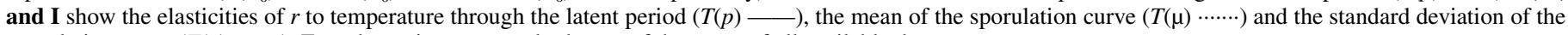
sporulation curve $(T(\mu)---)$. Error bars give one standard error of the mean of all available data years. 
experimental setups and the effect of this life cycle component has received much less attention. The lack of data on the precise effects of weather changes on the basic reproduction number might thus have led to the general but incorrect idea that it is the latent period rather than the basic reproduction number that contributes most to the yellow rust growth rate in the winter months $(3,26)$.

Light quantity is not important. Light has been suggested to have a considerable effect on the growth rate of yellow rust epidemics (5). These authors stated that the effects of this weather variable are closely linked with temperature. Despite the clear link between the two weather variables, i.e., in general temperature increases with increasing light quantity (Fig. 1), the link in their effects on the pathogen population growth rate is not reflected in our results. We, like McGregor and Manners (15), conclude that light quantity has to be taken into consideration, but unlike temperature, is not likely to become a limiting factor. These results show the importance of considering multiple weather variables simultaneously for observed weather patterns as previously suggested by Park (17). Studying light quantity effects in isolation would suggest a high relevance of this weather variable, whereas when compared with other weather variables its relevance decreases considerably.

Our findings that light through the basic reproduction number has one of the smallest elasticities from spring up to and including mid-autumn does not underpin the statement by de VallavieillePope et al. (5), that the increased yellow rust population development in spring can be explained by the increased light quantity in spring, leading to an increased leaf area. Our results do however correspond well with those of te Beest et al. (23), who found a weak relationship between the pathogen population growth rate and light quantity across the wheat growing season with a slight increase in the importance of light quantity in the winter months.

Infectious period contributes little to changes in yellow rust epidemic growth rates. Zadoks (26) and Luo and Zeng (13) found that the length of the infectious period of yellow rust has little effect on the pathogen population growth rate. We find that the effect of temperature through the mean and the standard deviation of the sporulation curve, which are measures of the infectious period, in general have the lowest elasticities (Fig. 2C, $\mathrm{F}$, and I). The results in this paper thus agree with previous findings with respect to the effect of the infectious period.

How does this all relate to pathogen occurrence/outbreaks? Comparing the results of our elasticity analysis with observed disease incidences (9), it becomes clear which period of the year separates places with high or low disease incidences. During the crop growing season at Rothamsted the high summer temperatures have a strong negative effect on spore production and thus the basic reproduction number (Fig. 2B), whilst all other effects and the maximum exponential growth rate of the pathogen population (results not shown) are similar between sites. Combined with the fact that yellow rust is defined as a cool climate pathogen $(8,21,24)$ this suggests that the Rothamsted site should experience the lowest yellow rust disease pressure. However, on average the yellow rust severity is highest at Rothamsted (9).

The higher disease pressures at Rothamsted as compared to those found at Glensaugh can potentially be explained by the higher winter temperatures at this site (Fig. 1). Because of the higher winter temperatures at Rothamsted the pathogen population increases earlier in the season and will thus at the start of the wheat growing season have built up a much higher inoculum pressure on volunteer plants and the crop rosette stage. This would also explain why Daamen et al. (3) found a positive correlation between the yellow rust severity in July and the average temperature between November and March. Similarly, te Beest et al. (23) found a correlation between increased winter temperatures and increased disease severity. Yellow rust is not able to reproduce below $-4^{\circ} \mathrm{C}$, but temperatures rarely get as low as this in the United Kingdom (26). Therefore, yellow rust will be able to reproduce throughout the year albeit at a very low rate on the coldest days of the year.

Like Daamen et al. (3) we thus conclude that it is the winter survival and not the summer survival $(17,26)$ of yellow rust that controls the eventual disease severity. This winter survival success then sets the start condition, i.e., inoculum pressure, for the next epidemic/growing season.

Advised United Kingdom farmer spraying regimes. In the United Kingdom there are three key developmental stages when it may be necessary to spray wheat crops against diseases (Fig. 1J): once upon the emergence of leaf 3, i.e., middle to late April; once upon the emergence of the flag leaf, i.e., middle to end of May and once post-ear emergence, i.e., mid-June (9). The third spray is seldom required specifically for yellow rust control, unless earlier treatments have been mis-timed due to adverse weather for spraying.

In middle to late April, when the first spray is applied, temperature and surface wetness duration through the basic reproduction number have by far the largest elasticity, whereas in middle to late May, when the second spray is applied, temperature through the latent period has an equally large elasticity (Fig. 2B, E, H, and J). It seems most sensible to apply sprays that at the time of application affect the life cycle component that is most sensitive to changes in the weather variables. Our results thus suggest that the first spray should normally be a fungicide known to be a protectant, which mainly affects the infection rate and thus the basic reproduction number. The second spray then should also have curative activity, which affects the latent period and the mean of the sporulation curve. However, the unpredictable weather makes it very difficult to time the sprays accurately and, therefore, farmers often apply fungicide products with both protectant and curative action in each spray (9).

Conclusions. A generic method was developed to study the elasticity of the exponential epidemic growth rate of a pathogen to weather changes, through its separate life cycle components. The elasticity analysis allows for a direct comparison between the effects of the various weather variables. By linking the method to observed weather patterns we were able to study the effects of multiple weather variables simultaneously and within realistic ranges. Moreover, the generic nature of the method enables us to compare different pathosystems with one unified model. The example of the application to yellow rust on wheat shows the potential of our method to disentangle the weather, life cycle, and epidemic development chain.

\section{ACKNOWLEDGMENTS}

This project has been funded by the Department for Environment, Food and Rural Affairs (Defra). Rothamsted Research receives support from the Biotechnology and Biological Sciences Research Council (BBSRC) of the United Kingdom.

\section{LITERATURE CITED}

1. Caswell, H. 2001. Matrix Population Models. 2nd ed. Sinauer Associates Inc., Sunderland, MA.

2. Chen, X. M. 2005. Epidemiology and control of stripe rust [Puccinia striiformis f. sp. tritici] on wheat. Can. J. Plant Pathol. 27:314-337.

3. Daamen, R. A., Stubbs, R. W., and Stol, W. 1992. Surveys of cereal diseases and pests in the Netherlands. 4. Occurrence of powdery mildew and rusts in winter-wheat. Neth. J. Plant Pathol. 98:301-312.

4. de Vallavieille-Pope, C., Huber, L., Leconte, M., and Goyeau, H. 1995. Comparative effects of temperature and interrupted wet periods on germination, penetration, and infection of Puccinia recondita f. sp. tritici and $P$. striiformis on wheat seedlings. Phytopathology 85:409-415.

5. de Vallavieille-Pope, C., Huber, L., Leconte, M., and Bethenod, O. 2002. Preinoculation effects of light quantity on infection efficiency of Puccinia striiformis and P. triticina on wheat seedlings. Phytopathology 92:13081314. 
6. Dennis, J. I. 1987. Temperature and wet-period conditions for infection by Puccinia striiformis f. sp. tritici race ${ }_{104} \mathrm{E}_{137} \mathrm{~A}+$. T. Brit. Mycol. Soc. 88:119-121.

7. Fitter, A. H., and Hay, R. K. M. 1987. Environmental Physiology of Plants. Harcourt Brace Jovanovich, London.

8. Gareth-Jones, D., and Clifford, C. 1983. Cereal Diseases. Their Pathology and Control. 2nd ed. John Wiley \& Sons, NY.

9. HGCA. 2006. The wheat disease management guide. HGCA, London.

10. Huber, L., and Gillespie, T. J. 1992. Modelling leaf wetness in relation to plant disease epidemiology. Annu. Rev. Phytopathol. 30:553-577.

11. Kranz, J., and Rotem, J. 1987. Experimental Techniques in Plant Epidemiology. Springer-Verlag, Berlin.

12. Lovell, D. J., Hunter, T., Powers, S. J., Parker, S. R., and van den Bosch, F. 2004. Effect of temperature on latent period of Septoria leaf blotch on winter wheat under outdoor conditions. Plant Pathol. 53:170-181.

13. Luo, Y., and Zeng, S. M. 1995. Simulation studies on epidemics of wheat stripe rust (Puccinia striiformis) on slow-rusting cultivars and analysis of effects of resistance components. Plant Pathol. 44:340-349.

14. McCree, K. J. 1981. Photosynthetically active radiation. Encyclopedia of plant physiology. Pages 41-55 in: Physiological Plant Ecology, I: Responses to the Physical Environment. O. L. Lange, P. S. Nobel, C. B. Osmond, and H. Ziegler, eds. Springer-Verlag, Berlin.

15. McGregor, A. J., and Manners, J. G. 1985. The effect of temperature and light intensity on growth and sporulation of Puccinia striiformis on wheat. Plant Pathol. 34:263-271.

16. Papastamati, K., and van den Bosch, F. 2007. The sensitivity of the epidemic growth rate to weather variables, with an application to yellow rust on wheat. Phytopathology 97:202-210.

17. Park, R. F. 1990. The role of temperature and rainfall in the epidemiology of Puccinia-striiformis f. sp. tritici in the summer rainfall area of Eastern Australia. Plant Pathol. 39:416-423.

18. Pivonia, S., and Yang, X. B. 2006. Relating epidemic progress from a general disease model to seasonal appearance time of rusts in the United States: Implications for soybean rust. Phytopathology 96:400-407.

19. Rapilly, F. 1979. Yellow rust epidemiology. Annu. Rev. Phytopathol. 17:59-73.

20. Segarra, J., Jeger, M. J., and van den Bosch, F. 2001. Epidemic dynamics and patterns of plant diseases. Phytopathology 91:1001-1010.

21. Singh, R. P., Huerta-Espino, J., and Roelfs, A. P. 2002. The wheat rusts. In Bread wheat. Improvement and production. B. C. Curtis, S. Rajaram, and H. Gómez-Macpherson, eds. Agriculture Department of the United Nations.

22. Szeicz, G. 1974. Solar radiation in crop canopies. J. Appl. Ecol. 11:11171156.

23. te Beest, D. E., Paveley, N. D., Shaw, M. W., and van den Bosch, F. 2007. Disease-weather relationships for powdery mildew and yellow rust on winter wheat. Phytopathology (In Press.)

24. Wiese, M. V. 1987. Compendium of Wheat Diseases. American Phytopathological Society, St. Paul, MN.

25. Xu, X. M., Butt, D. J., and VanSanten, G. 1995. A dynamic model simulating infection of apple leaves by Venturia inaequalis. Plant Pathol. 44:865-876.

26. Zadoks, J. C. 1961. Yellow rust on wheat studies in epidemiology and physiologic specialization. Tijdschr. ver Plantenziekten 67:69-256. 